\title{
The COVID-19 wicked problem in public health ethics: conflicting evidence, or incommensurable values?
}

Federica Angeli (10 ${ }^{1 凶}$, Silvia Camporesi (i] ${ }^{2} \&$ Giorgia Dal Fabbro ${ }^{3}$

While the world was facing a rapidly progressing COVID-19 second wave, a policy paradox emerged. On the one side, much more was known by Autumn 2020 about the mechanisms underpinning the spread and lethality of Sars-CoV2. On the other side, how such knowledge should be translated by policymakers into containment measures appeared to be much more controversial and debated than during the first wave in Spring. Value-laden, conflicting views in the scientific community emerged about both problem definition and subsequent solutions surrounding the epidemiological emergency, which underlined that the COVID-19 global crisis had evolved towards a full-fledged policy "wicked problem". With the aim to make sense of the seemingly paradoxical scientific disagreement around COVID-19 public health policies, we offer an ethical analysis of the scientific views encapsulated in the Great Barrington Declaration and of the John Snow Memorandum, two scientific petitions that appeared in October 2020. We show that how evidence is interpreted and translated into polar opposite advice with respect to COVID-19 containment policies depends on a different ethical compass that leads to different prioritization decisions of ethical values and societal goals. We then highlight the need for a situated approach to public health policy, which recognizes that policies are necessarily value-laden, and need to be sensitive to context-specific and historic socio-cultural and socioeconomic nuances.

\footnotetext{
${ }^{1}$ University of York Management School, University of York, York, UK. ${ }^{2}$ Department of Global Health and Social Medicine, King's College London, London, UK. ${ }^{3}$ School of International Studies, University of Trento, Trento, Italy. ${ }^{凶}$ email: federica.angeli@york.ac.uk
} 


\section{Competing goals and conflicting values in the COVID-19 wicked problem}

$\mathrm{t}$ the time of writing (November 2020), while the world is facing a rapidly progressing COVID-19 second wave, and governments are rushing towards the reintroduction of restrictive measures, the consensus that almost monolithically surrounded the lockdown decisions-or slight variations of the same formula-in Spring 2020, is visibly breaking apart. Roughly 6 months into the pandemic, a paradox emerges. On the one hand, we have more evidence about the mechanisms underpinning the transmission, morbidity and mortality related to Sars-CoV-2. On the other hand, how such knowledge should be translated into containment policies is subject of fierce debates. In particular, a polarization of views started to emerge within the scientific community, vividly illustrated by the Great Barrington Declaration (Kulldorff et al., 2020; Lenzer, 2020) on the one side and the John Snow Memorandum (Alwan et al., 2020; John Snow Memorandum, 2020) on the other side. The Great Barrington Declaration was authored by Dr. Sunetra Gupta (University of Oxford), Dr. Jay Bhattacharya (Stanford University), and Dr. Martin Kulldorff (Harvard University), and was written and signed at the American Institute for Economic Research in Great Barrington, Massachusetts, on October 4th 2020. The document is co-signed by a further 44 medical and public health scientists and medical practitioners working in the US, Canada, Israel, Germany, India, New Zealand, and Sweden. The declaration advocates against lockdown measures to favor a containment approach based on a focused protection of the vulnerable, whilst allowing the segments of the population nominally at lower risk of COVID-related complications to resume normal life, thus favouring population-level natural immunity. The John Snow Memorandum was published in the Lancet on October 15th, 2020 as a reaction to the Great Barrington declaration, and was authored by a team of 31 scientists from the UK, Switzerland, US, Canada, Germany, France, Australia. The memorandum's aim was to lay out empirical evidence to justify restrictive lockdownlike measures to prevent the uncontrolled spread of the virus and the subsequent collapse of healthcare systems.

Such value-laden, conflicting views about both problem definition and problem solution are typical of policy "wicked problems" (Alford and Head, 2017), a construct that increasingly applies to the COVID-19 global crisis. The pandemic has created a context in which multiple urgent, interdependent societal goals simultaneously exist, which generates a fundamental problem of prioritization of one aspect over another (Camporesi and Mori, 2020). Such goals can be identified in the short-term reduction of COVID-19 morbidity and mortality, the mitigation of long-term social repercussions of containment policies (rising social inequalities, mental health issues due to social isolation, intergenerational conflicts) and financial adverse consequences, in the form of severe economic recessions, and subsequent rise in unemployment, poverty levels, and social tensions (Angeli and Montefusco, 2020; Camporesi, 2020). We are currently witnessing how such prioritization choices generate conflicting stakeholder views about what the problem is (e.g., catastrophic death toll vs potential economic meltdown) and the related solutions (e.g., lockdown measures vs softer mechanisms of virus control). A full-fledged wicked problem has now arisen. However, while wicked problems are normally associated with policy choices, the polarization of views has now permeated the scientific community and the very process of translation of evidence into policy advice, therefore illustrating-perhaps more than ever beforethe evolution from value-free to value-laden science.

The prioritization of the shorter-term goals of reduction of COVID-19-related morbidity and mortality in the Spring of 2020 first wave resulted in a multiplicity of policy interventions' bundles in different countries. These interventions shared similarities in the way they restricted individual freedoms (Camporesi, 2020) and varied in their combination of school closures, limitations on pubs' and restaurants' opening times, use of face coverings, restrictions of socialization opportunities or individual mobility (Angeli and Montefusco, 2020). Now, as evidence about modes of contagion and manifestations of the disease accumulates, the debate about how to use the scientific evidence to inform policy has reached the stage of a polarized conflict. The shift away in narrative from the "we are all in this together" (United Nations, 2020), to the "focused protection" (Kulldorff et al., 2020) shows that the COVID -19 wicked policy problem requires more in-depth ethical considerations. In this piece, we offer an ethics-driven view of scientific advice for COVID-19 policy formulation, to illustrate how specific ethical prisms can lead to different-even polar opposite-views on containment policies. In this sense, we highlight the importance of ethics in decision-making and in the process of translating evidence into policy design (Oliver and Boaz, 2019). Our analysis also aims to provide an interdisciplinary interpretative lens, as it addresses the problem of how decision-makers attend to multiple objectives in space and time-a well-known area of research in management studies (Cyert and March, 1963; Ocasio, 1997; Rerup, 2009), by theoretically drawing on the field of public health ethics (Abbasi et al., 2018), and public policy formulation in the context of wicked problems (Head, 2008; Waddell, 2016).

\section{Conflicting policy viewpoints: different priorities to different values}

Conflicting values are commonplace in the context of managerial decision-making (e.g., Levinthal and Marengo, 2020) and in public health, especially in relation to the management of infectious diseases (Ortmann et al., 2016). Compulsory vaccination represents one emblematic example, in which individual freedom is restricted to favor the public good, by way of boosting heard immunity towards specific pathogens (Dawson et al., 2007). Public health policies revolve, although often implicitly, around a compass of three key values, namely utility, liberty, and equity/ equality. The principle of utility aims at maximizing a certain value "X" for the greatest number of people. Public health policies aim at maximizing population health. In the context of measures aimed at the containment of disease outbreak, ensuring population health translates into reducing the disease transmission, morbidity and mortality, whether through vaccination, natural herd immunity, or restrictive measures aimed at reducing/modifying citizens' socialization and interaction patterns, mobility and hygiene practices. Liberty is generally understood as the freedom to live one's own life free from interference from others. Although there are two main understandings of liberty, a negative (liberty to act free from interference), and a positive one (liberty to shape one's own life according to one's own values, and to have the opportunity to do so beyond and above the lack of others' interference) (Berlin, 1969) in the context of public health, liberty is generally conceptualized as negative liberty. Equity/equality is a value that is recognized as salient for public health policies, but also of difficult operationalization and implementation. Egalitarianism is the theory that aims at ensuring a fair distribution of benefits and harms across a given population, and hence to maintain distributive justice. Equity and equality are often used as synonyms in public health ethics, however, they point to different -even opposite-concepts. Equity is a normative concept, grounded in distributive justice, while that is not necessarily the case for equality (i.e. not all health inequalities are unfair) (Braveman and Gruskin, 2003). In the context of public health policies, equity means equal opportunity and implies that 
resources should be distributed in ways most likely to produce a fair distribution of harms and benefits across all segments of the population. This often implies that societal groups should not be offered the same services (as it would be in the case of equal treatment) but rather should receive differential care according to their differential needs. We will focus in this piece on equity rather than equality.

Even if not explicitly acknowledged, the values of utility, liberty and equity underpin any public (health) policy decision, including those aimed at containing the COVID-19 emergency. According to a pluralistic approach to public health policy (Selgelid, 2009b, 2009a) these three values should all be considered as independent, socially legitimate public goals. Effective public health policies are then tasked to find creative ways to pursue all of them at the same time, through trade-offs that are socially and culturally acceptable. This is naturally easier said, than done. What creates a broad spectrum of public policy approaches in response to the COVID-19 pandemic is the different weight associated by different decision-makers-and also by scientists-to the three value dimensions of the ethical compass, resulting in different trade-off points. The recently published Great Barrington Declaration and John Snow Memorandum exemplify two situations in which, provided the same available scientific evidence, this is interpreted and translated by scientists into polar opposite advice with respect to COVID-19 containment policies. We argue that such views can be best understood in light of a different ethical compass that leads to different prioritization decisions. We can assume that signatories to both memoranda obviously want to reduce COVID-19 morbidity and mortality, want to mitigate its socioeconomic repercussions, are concerned about restrictions of personal freedom and increasing surveillance, appreciate the differential impact of the policies across the population. However, the signatories assign a different weight to each of the three values of utility, liberty and equity, hence appraising the available scientific evidence with a different, value-laden ethical prism. The fact that the process of normative weighting assigned to empirical data remains implicit creates a polarization that is only apparently based on disagreements about empirical evidence.

The Great Barrington declaration takes a stance against restrictive measures aimed at controlling the community spread of the virus and instead proposes to focus policies and societal resources towards "focused protection" of the older demographics - notably those who are several times more likely to die from COVID-19 or to suffer from long-lasting complications. According to the signatories, this approach would also favor the development of herd immunity, hence further shielding the older people from the possibility of contracting the disease. This position has sparked a strong reaction from the signatories of the John Snow Memorandum, which highlights instead that the herd immunity arguments based on the assumption that natural infection from the virus will boost lasting protective immunity are flawed and lack supporting evidence. Moreover, the uncontrolled spread of Sars-CoV-2 within communities would lead to an excessive burden on healthcare systems and workers, and compromise the diagnosis and treatment of several acute and chronic conditions, with long-lasting-negative repercussions. As a consequence, the John Snow Memorandum argues that it is important to extend social distancing, targeted restrictions of mobility and socialization, face coverings and strengthened hygiene practices to the whole population.

With its emphasis on "focused protection" the Great Barrington declaration prioritizes values of liberty and equity, as it views the wide imposition of restrictive measures as violating individual freedom in a way that is unfair to the less vulnerable individuals, such as the young generations. The herd immunity argument- widely decried by the scientific community (Aschwanden, 2020) and public opinion alike (The Guardian, 2020)-is highly controversial, and mostly for an ethical rather than a scientific reason. The technical possibility that a population develops natural protection from the infection exists, however, for Sars-CoV-2 it is unclear what the threshold is as this depends on the transmission rate and how long the immunity could last (Fontanet and Cauchemez, 2020). Although from a technical point of view the pursuit of (short-term) herd immunity is not, in theory, an unattainable policy goal, there is widespread societal consensus that it would be an unacceptable policy goal from an ethical point of view, in the absence of improved patient management and in the absence of optimal shielding of individuals at risk of severe complications. In the absence of these two key factors, current modeling of transmission dynamics predict that letting Sars-CoV2 epidemic run its course without non-pharmaceutical interventions (i.e., social distancing, facemasks, heightened hygiene measures) would lead to catastrophic consequences in terms of death toll, both direct from COVID-19, and indirect, due to the overwhelming burden on the healthcare systems (hospital capacity) (Brett and Rohani, 2020).

The signatories of the John Snow Memorandum are in fact more concerned with utility, namely the short-term reduction of COVID-19-induced mortality and morbidity and the long-term health outcomes of delayed treatments. Interestingly, by problematizing the definition of "vulnerable" individuals, John Snow supporters implicitly defend the egalitarianism of their position, as evidence is still scant around the reasons underpinning the wide individual variation in COVID-19 adverse outcomes-with some developing grave complications until death and other showing only mild symptoms or remaining completely asymptomatic. Concluding that everyone is equally at risk, the John Snow Memorandum implicitly assumes that it is fair for restrictive measures to be applied to everyone, therefore leaning towards a solution geared towards equality rather than equity. Instead, the Great Barrington Declaration implicitly proffers that vulnerability to the virus is only one aspect that should be taken into account. Vulnerabilities within the population instead should be specified taking into account vulnerability towards negative repercussion of the economic recessions-such as BAME minorities in the UK (Institute for Fiscal Studies, 2020), as well vulnerability towards the negative effects of lockdown-induced isolation and alienation, as in adolescents (Lee, 2020). The prioritization of short-term gains in terms of physical health with respect to impeding longer term socio-economic disadvantage and mental health consequences therefore becomes less straightforward.

\section{Contextualizing values and policies in time and space}

In dealing with a highly complex situation-a wicked problemsuch as the COVID-19 pandemic, it is important to understand how values-hence societal goals-are formulated and understood, and the influence of temporality. The value of utility can be specified short-term, as the reduction in the number of COVID19-related deaths at a given time. However, a more encompassing, forward-looking view will also consider the total number of COVID-19-induced deaths in the medium-long run. The need to prioritize COVID patients in the hospital will necessarily lead to other collateral deaths because of missed appointments and delayed surveillance or surgeries (Maringe et al., 2020). Economic recession is widening inequalities and increasing poverty levels (Kirby, 2020; Van Lancker and Parolin, 2020), while the mental health repercussions induced by isolation especially in young people might lead to forms of addiction and depression (Lee, 2020). While deaths from the infectious disease are short-term, indirect casualties that will occur down the line need to be taken 
into account. Public health policies cannot afford the myopic mistake of discounting the future, a well-known individual cognitive bias (Trout, 2007). The public health ethics framework also demands that the management of infectious diseases outbreaks follows the key principle of proportionality in restricting individual freedoms to promote the public good (World Health Organization, 2020). This means that, as epidemiological and clinical evidence becomes more conclusive on the disease's transmission, prevention and diagnosis patterns (Manigandan et al., 2020), on the variability of health outcomes (Chen et al., 2020), on the effect of non-pharmaceutical interventions to reduce community spread ( $\mathrm{Li}$ et al., 2020), and on the long-term consequences of lockdown measures such as school closures (Bayham and Fenichel, 2020; Viner et al., 2020), the same restrictive policies might not be as suitable, justified or acceptable as they were in the early stage of the pandemic. This principle is implicit in the Great Barrington declaration.

What degree of personal infringement of liberty is justified? This is where ethics comes in. Expert groups will offer a range of possible ethically justified policies, but, we argue, it is the policymakers' task to do the normative weighting and to decide which policy approach is best suited to the local socio-economic, socio-cultural and socio-political context (Angeli and Montefusco, 2020). While in some national settings the Great Barrington Declaration proposal could be more attuned to the existing social dynamics, individual mindsets, healthcare infrastructure and economic development, in other contexts the prescription of the very same proposal would not be applicable nor recommended, while the solutions proposed by the polar opposite John Snow Memorandum could be more suitable. For example, a policy of focused protection is not practical in settings-such as Italy-where intergenerational exchange is very high, grandparents often babysit grandchildren and even share living space with younger generations. A focused protection approach, which also aims at achieving high levels of community spread of the disease in less vulnerable societal segments, will likely lead to higher burden on the healthcare system, which is only sustainable in settings where healthcare infrastructures are strong and widely accessible, and focused protection of vulnerable segments of the population (i.e shielding) is feasible. In a similar way, restrictions to individual freedom are more difficult to implement in countries where personal liberty is culturally highly valued, and where utility-intended as the public good-comes second. A case in point is the use of face coverings, which, despite mounting evidence related to the importance of the measure to prevent COVID-19 transmission (Cheng et al., 2020; Lyu and Wehby, 2020), remains highly debated (Martin et al., 2020). It is not by chance that more individualistic cultures such as the United States, the United Kingdom or the Netherlands (Hofstede, 1983), have seen a more patchy and less widespread imposition of such measures (Royal Society, 2020; Statista, 2020), combined with higher societal resistance and rising social tensions (CNN, 2020).

Finally, questions of equity and justice. Public health measures aimed at containing an infectious disease outbreak should take into account to what degree the measures are disproportionately affecting certain groups of the population. This is where the concept of vulnerability comes in and where it can be used to operationalize the equity principle. Defining who qualifies as vulnerable is difficult, but by no means impossible, as research ethics literature demonstrates. One approach that we think could be well suited here is the layered approach to vulnerability (Luna, $2019,2014)$, which is context dependent, and dynamic. One could identify, for example, the following three layers of COVID-19 related vulnerability:
- A biological axis: likelihood of developing severe/critical symptoms after contracting COVID-19. Evidence widely supports that older people and people with pre-existing comorbidities are at higher risk of COVID complications;

- Socio-economic axis: likelihood of being severely affected by restrictive measures. Studies have highlighted how disadvantaged groups and communities (such as BAME minorities in the UK) are disproportionally more severely hit by the economic crisis ensuing from lockdown measures;

- Mental health axis: likelihood of developing severe mental health repercussions related to containment policies. School closures and extended lockdown periods have increased mental health issues in the population, with children and adolescents at particularly high risk.

Age, gender and race remain transversal axes here, as the approach rejects applying the label of vulnerability to specific groups. That does not mean that is impossible to define who is vulnerable, contrary to the John Snow memorandum positions. However, who counts as vulnerable to COVID-19 will change depending on the context, over time and through what layers one decides to look at this question. While in the first COVID-19 wave the priority has been given to the biological axis, the attention is, in the second COVID-19 wave, importantly shifting towards socio-economic and mental health aspects.

With the purpose of illustrating the longitudinal evolution over time of value prioritization, and its cross-sectional, crosscountry variation, we have selected a number of containment measures that can reflect how the values of liberty, equality and utility are incorporated into scientific advice and then translated into policy. Restrictions to individual freedom can be appreciated for example through the presence of restrictions to jogging activities; the presence of a ban on amatorial sports activities; the extent of face coverings obligations, the restrictions on household mixing, and whether a social bubble is allowed. The value of equity can be operationalized into whether the measures have been prescribed to the whole population indistinctively or whether there has been a differential application to more or less vulnerable sub-groups, or taking into account the different morbidity and mortality levels across regions. This aspect can be appreciated by considering whether restrictions have been imposed nationally or following a regionalization rationale; whether face coverings have been prescribed also to children under 11, notably less amenable to infect, get infected and develop severe symptoms from COVID-19; whether specific measures have been adopted to strengthen protection of older demographics; whether youth sport activities have been allowed; whether business closures have been imposed indistinctively or have instead followed an occupational health risk assessment. Finally, utility can reflect into governments' advocacy practices, namely the presence of a stay-at-home advice, the emphasis of COVID-19 as a burden for healthcare workers and systems, the clear and frequent communication of COVID-19 epidemic progression, the level of surveillance and sanctioning of noncompliant individual behaviors. We have considered the presence/absence as well as the strength of the above aspects at the highest point of first and second wave of COVID-19, in Italy and in the United Kingdom. As restriction levels, timing and the combination varied across England, Scotland, Wales and Northern Italy, we focused on England.

Table 1 represents the comparison of measures between COVID-19 first and second wave in the two countries, as derived from the original policy documents. Based on the nature of the containment measures, and the effect to which they reflected values of equity, utility and liberty, we computed scores on each 


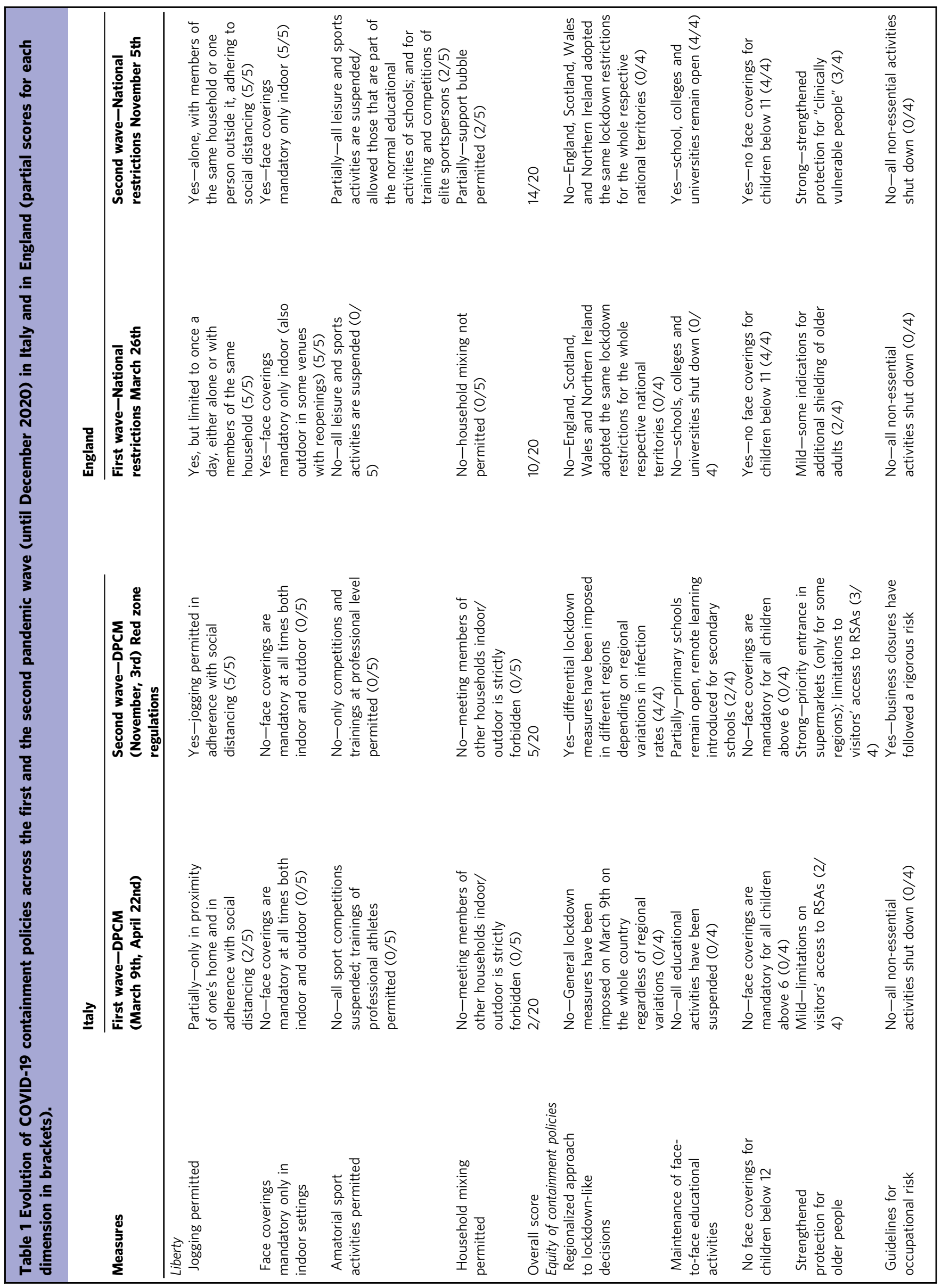




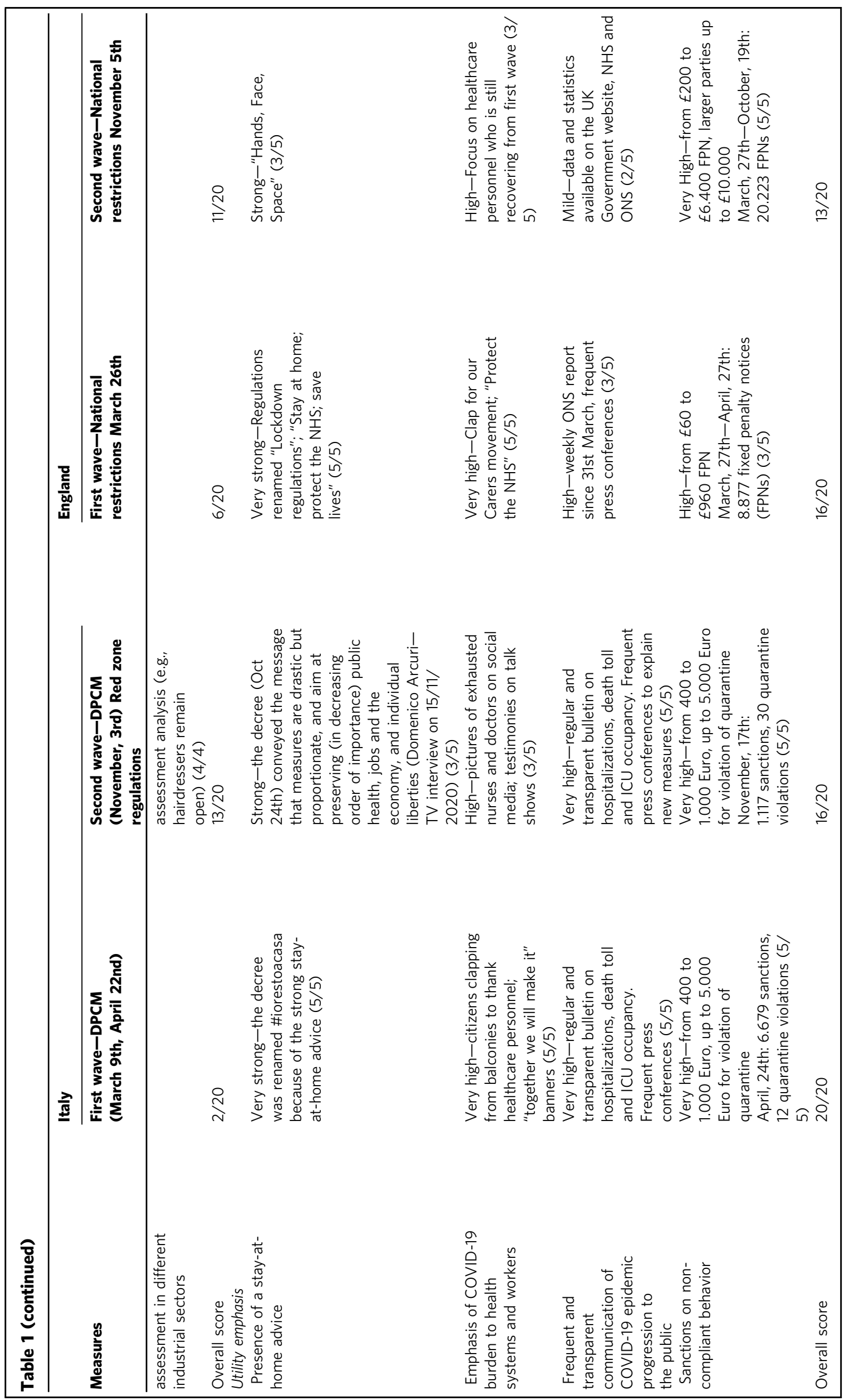



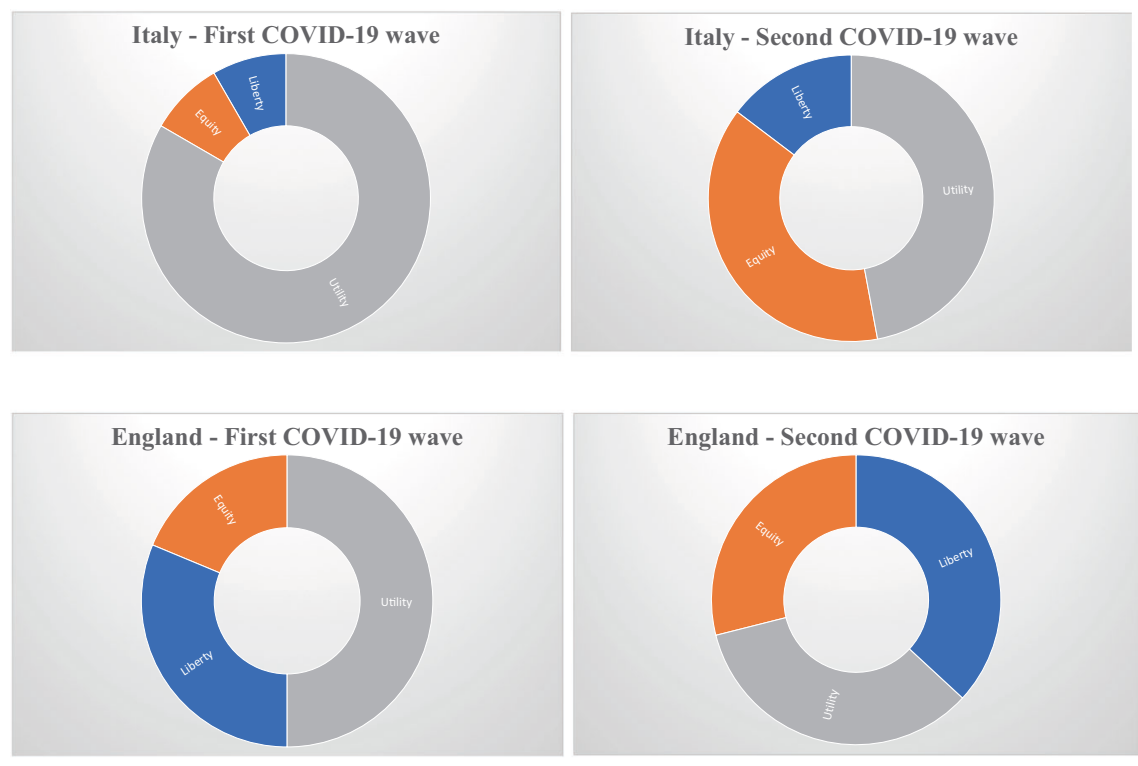

Fig. 1 Evolution of value trade-off. Evolution of the value trade-off embedded in the COVID-19 containment policies promulgated in Italy and in England, during the first and the second pandemic wave (until December 2020).

dimension, for each country across the two waves, on a total of 20 points for each value dimension.

We then plotted the results in Fig. 1. The graphs highlight how values are differentially embedded into containment policies trough context- and time-specific trade-offs. The figure highlights how two countries started from very different positions, with measures in Italy in the first wave almost entirely guided by utility (public health) considerations, with strong restrictions of individual freedoms and little appreciation of differences in vulnerability levels across populations and regions. In the second wave, we notice the evolution of Italian policies towards more consideration for liberty and equity value dimensions. England has experienced a similar evolution, albeit starting from a much more libertarian stance. Its policies show an evolution towards liberty and equity considerations against a slight reduction of utilityfocused measures.

\section{Conclusions}

Public health policies-and particularly those aimed at the containment of a highly infectious disease such as COVID-19revolve around a compass of moral values, which are often implicitly given different weights by both policymakers and scientific advisors. Both the understanding of these values, and the normative weighing of the values will always necessarily be context dependent, and dynamic. Public health policies should aim to consider to what degree the proposed measures aimed to preserve the public good are socio-culturally acceptable in restricting individual freedom, in what way they disproportionately affect certain groups of the population, according to what aspect of vulnerability is most relevant. An approach of situated policy is therefore most salient, which promotes policymaking that is attuned with idiosyncrasies that are both spatial (the socio-cultural and socio-economic local context) and temporal (given the rapid evolution of COVID-related scientific evidence). A situated approach to policymaking in the context of wicked problems reflects that there cannot be a one-size-fits-all approach to COVID-19 public health policies.

Our analysis has aimed to propose an ethics-driven perspective to better comprehend how evidence is used to inform policymaking and how disagreement on policy can emerge within scientific communities. In doing so, we have offered an interdisciplinary view at the intersection between management studies, public policy and bioethics disciplinary boundaries. Whilst the debate around evidence-based policymaking has been a core focus of science and technology studies (Frickel and Moore, 2006), this commentary offers an alternative perspective that is less concerned with the politics of science-hence the influence on knowledge production of socio-political factors and power dynamics (Hoppe, 2005) - and is instead more focused on how evidence is filtered through a situated ethical prism to inform policymakers' prioritization decisions. The recognition that policymaking is shaped by socio-contextual factors and that policymakers engage into processes of interpretation of evidence in light of their knowledge, norms and values and towards their economic and political goals is not new (Sohn, 2018). This commentary suggests, however, that an ethical perspective is salient to understand such processes, that interestingly affect not only policymakers but also prominent representatives of the scientific community. Our analysis thus highlighted how evidence-based public health containment measures to address the pandemic can be ethically justifiable and understood through a clear and transparent understanding of the values underpinning policy decisions, and the evolution of acceptable trade-offs over time.

Received: 20 November 2020; Accepted: 1 June 2021;

Published online: 30 June 2021

\section{References}

Abbasi M, Majdzadeh R, Zali A, Karimi A, Akrami F (2018) The evolution of public health ethics frameworks: systematic review of moral values and norms in public health policy. Med Heal Care Philos 21:387-402

Alford J, Head BW (2017) Wicked and less wicked problems: a typology and a contingency framework. Policy Soc 36:397-413

Alwan NA, Burgess RA, Ashworth S, Beale R, Bhadelia N, Bogaert D, Dowd J, Eckerle I, Goldman LR, Greenhalgh T, Gurdasani D, Hamdy A, Hanage WP, Hodcroft EB, Hyde Z, Kellam P, Kelly-Irving M, Krammer F, Lipsitch M, McNally A, McKee M, Nouri A, Pimenta D, Priesemann V, Rutter H, Silver J, Sridhar D, Swanton C, Walensky RP, Yamey G, Ziauddeen H (2020) Scientific consensus on the COVID-19 pandemic: we need to act now. Lancet 396:e71-e72 
Angeli F, Montefusco A (2020) Sensemaking and learning during the Covid-19 pandemic: a complex adaptive systems perspective on policy decisionmaking. World Dev 136:1-4

Aschwanden C (2020) The false promise of herd immunity for COVID-19. Nature 587:26-28

Bayham J, Fenichel EP (2020) Impact of school closures for COVID-19 on the US health-care workforce and net mortality: a modelling study. Lancet Public Heal 5:e271-e278

Berlin I (1969) Two concepts of Liberty. In: Berlin I (eds) Four essays on Liberty. Oxford University Press, Berlin

Braveman P, Gruskin S (2003) Defining equity in health. J Epidemiol Community Health 57:254-258

Brett TS, Rohani P (2020) Transmission dynamics reveal the impracticality of COVID-19 herd immunity strategies. Proc Natl Acad Sci USA 117:25897-25903

Camporesi S (2020) It didn't have to be this way reflections on the ethical justification of the running ban in northern italy in response to the 2020 COVID19 outbreak. Bioethical Inquiry 17:643-648. https://doi.org/10.1007/s11673020-10056-1

Camporesi S, Mori M (2020) Ethicists, doctors and triage decisions: who should decide? And on what basis? Journal of Medical Ethics Published Online First: 10 July 2020. https://doi.org/10.1136/medethics-2020-106499

Cheng KK, Lam TH, Leung CC. (2020). Wearing face masks in the community during the COVID-19 pandemic: altruism and solidarity. Lancet (London, England), S0140-6736(20)30918-1. Advance online publication. https://doi. org/10.1016/S0140-6736(20)30918-1

Chen Y, Tong X, Li Y, Gu B, Yan J, Liu Y, Shen H, Huang R, Wu C (2020) A comprehensive, longitudinal analysis of humoral responses specific to four recombinant antigens of SARS-CoV-2 in severe and non-severe COVID-19 patients. PLoS Pathog 16:e1008796

CNN (2020) London face mask protests: Hundreds of people, some wearing masks, protested against mask-wearing-CNN. https://edition.cnn.com/2020/07/20/ uk/london-face-mask-protest-gbr-intl/index.html

Cyert R, March JG (1963) A behavioral theory of the firm. Prentice Hall, Englewood Cliffs, NJ

Dawson A, Verweij M, Verweij MF (2007) Ethics, prevention, and public health. Oxford University Press on Demand. Oxford University Press, Oxford, UK

Fontanet A, Cauchemez S (2020) COVID-19 herd immunity: where are we? Nat Rev Immunol 20:583-584

Frickel S, Moore K (2006) The new political sociology of science: Institutions. Networks, and Power. The University of Wisconsin Press, Madison

Graham P. Martin, Esmée Hanna, Margaret McCartney, Robert Dingwall (2020) Science, society, and policy in the face of uncertainty: reflections on the debate around face coverings for the public during COVID-19, Critical Public Health, 30:5, 501-508. https://doi.org/10.1080/09581596.2020.1797997

Head BW (2008) Wicked Problems in Public Policy. 3:29-30

Hofstede G (1983) National cultures revisited. Behav Sci Res 18:285-305

Hoppe R (2005) Rethinking the science-policy nexus: from knowledge utilization and science technology studies to types of boundary arrangements. Poiesis und Prax 3:199-215

Institute for Fiscal Studies (2020) COVID-19 and inequalities/Inequality: the IFS Deaton Review. https://www.ifs.org.uk/inequality/covid-19-and-inequalities/

John Snow Memorandum (2020) John Snow Memorandum. https://www. johnsnowmemo.com/

Kirby T (2020) Evidence mounts on the disproportionate effect of COVID-19 on ethnic minorities. Lancet Respir Med 8:547-548

Kulldorff M, Gupta S, Bhattacharya J (2020) Great Barrington Declaration. https:// gbdeclaration.org/

Van Lancker W, Parolin Z (2020) COVID-19, school closures, and child poverty: a social crisis in the making. Lancet Public Heal 5:e243-e244

Lee J (2020) Mental health effects of school closures during COVID-19. Lancet Child Adolesc Heal 4:421

Lenzer J (2020) Covid-19: Group of UK and US experts argues for "focused protection" instead of lockdowns. BMJ 371:m3908

Levinthal DA, Marengo L (2020) Organizations, ambiguity, and conflict: Introduction to the special issue in honor of James G. March. Ind Corp Chang 29:81-87

Li Y, Campbell H, Kulkarni D, Harpur A, Nundy M, Wang X, Nair H., \& for COVID, U. N. (2021). The temporal association of introducing and lifting non-pharmaceutical interventions with the time-varying reproduction number (R) of SARS-CoV-2: a modelling study across 131 countries. The Lancet Infectious Diseases, 21(2):193-202

Luna F (2019) Identifying and evaluating layers of vulnerability-a way forward. Dev World Bioeth 19:86-95

Lyu W, Wehby GL (2020) Community use of face masks and COVID-19: evidence from a natural experiment of state mandates in the US. Health Aff 39:1419-1425
Manigandan S, Wu MT, Ponnusamy VK, Raghavendra VB, Pugazhendhi A Brindhadevi K (2020) A systematic review on recent trends in transmission, diagnosis, prevention and imaging features of COVID-19. Process Biochem 98:233-240

Maringe C, Spicer J, Morris M, Purushotham A, Nolte E, Sullivan R, Rachet B, Aggarwal A (2020) The impact of the COVID-19 pandemic on cancer deaths due to delays in diagnosis in England, UK: a national, population-based, modelling study. Lancet Oncol 21:1023-1034

Luna L (2014) 'Vulnerability', an interesting concept for public health: the case of older persons. Public Health Ethics 7(2):180-194

Ocasio W (1997) Towards an attention-based view of the firm. Strateg Manag J 18:187-206

Oliver K, Boaz A (2019) Transforming evidence for policy and practice: creating space for new conversations. Nat Humanit Soc Sci Commun 5:1-10

Ortmann LW, Barrett DH, Saenz C, Bernheim RG, Dawson A, Valentine JA, Reis A (2016) Public Health Ethics: Global Cases, Practice, and Context. Public Health Ethics Analysis. Springer, Cham, pp. 3-35

Rerup C (2009) Attentional triangulation: learning from unexpected rare crises. Organ Sci 20:876-893

Royal Society T (2020) Face masks and coverings for the general public: Behavioural knowledge, effectiveness of cloth coverings and public messaging. Royal Society $\mathrm{T}$

Selgelid MJ (2009a) A moderate pluralist approach to public health policy and ethics. Public Health Ethics 2:195-205

Selgelid MJ (2009b) Pandethics. Public Health 123:255-259

Sohn J (2018) Navigating the politics of evidence-informed policymaking: strategies of influential policy actors in Ontario. Palgrave Commun 4:1-12

Statista (2020) Masks in Europe 2020 | Statista. https://www.statista.com/statistics/ 1114375/wearing-a-face-mask-outside-in-european-countries/

The Guardian (2020) Swedish surge in Covid cases dashes immunity hopes/World news|The Guardian. https://www.theguardian.com/world/2020/nov/12/ covid-infections-in-sweden-surge-dashing-hopes-of-herd-immunity

Trout JD (2007) The psychology of discounting: a policy of balancing biases. Public Aff Q 21:201-220

United Nations (2020) We are all in this Together: Human Rights and COVID-19 Response and Recovery United Nations. https://www.un.org/en/uncoronavirus-communications-team/we-are-all-together-human-rights-andcovid-19-response-and

Viner RM, Russell SJ, Croker H, Packer J, Ward J, Stansfield C, Mytton O, Bonell C, Booy R (2020) School closure and management practices during coronavirus outbreaks including COVID-19: a rapid systematic review. Lancet Child Adolesc Heal 4:397-404

Waddell S (2016) Societal change systems: a framework to address wicked problems societal change systems: a framework to address wicked problems. J Appl Behav Sci 52:422-440

World Health Organization (2020) WHO|Managing Ethical Issues in Infectious Disease Outbreaks. WHO

\section{Competing interests}

The authors declare no competing interests.

\section{Additional information}

Correspondence and requests for materials should be addressed to F.A.

Reprints and permission information is available at http://www.nature.com/reprints

Publisher's note Springer Nature remains neutral with regard to jurisdictional claims in published maps and institutional affiliations.

Open Access This article is licensed under a Creative Commons Attribution 4.0 International License, which permits use, sharing, adaptation, distribution and reproduction in any medium or format, as long as you give appropriate credit to the original author(s) and the source, provide a link to the Creative Commons license, and indicate if changes were made. The images or other third party material in this article are included in the article's Creative Commons license, unless indicated otherwise in a credit line to the material. If material is not included in the article's Creative Commons license and your intended use is not permitted by statutory regulation or exceeds the permitted use, you will need to obtain permission directly from the copyright holder. To view a copy of this license, visit http://creativecommons.org/ licenses/by/4.0/

(C) The Author(s) 2021 